\title{
Current state of the seismic broadband network of Indonesia: Is it possible for the early warning system from a subaerial source- induced tsunami?
}

\author{
Haekal A. Haridhi ${ }^{1,2,3,}{ }^{*}$, Dimas Sianipar ${ }^{4}$, Syahrul Purnawan ${ }^{1,3}$, Ichsan Setiawan ${ }^{1,3}$, Bor-Shouh Huang ${ }^{5}$ \\ ${ }^{1}$ Department of Marine Sciences, Faculty of Marine and Fisheries, Universitas Syiah Kuala, Banda Aceh 23111, Indonesia. \\ ${ }^{2}$ Tsunami and Disaster Mitigation Research Center (TDMRC), Universitas Syiah Kuala, Banda Aceh 23111, Indonesia. \\ ${ }^{3}$ Research Center for Marine Sciences and Fisheries, Universitas Syiah Kuala, Banda Aceh 23111, Indonesia. \\ ${ }^{4}$ Agency for Meteorology, Climatology, and Geophysics (BMKG), Jakarta 10610, Indonesia. \\ ${ }^{5}$ Institute of Earth Science, Academia Sinica, Taipei 115, Taiwan
}

\begin{abstract}
Lesson learned from the Anak Krakatau volcanic eruption followed by the tsunami on 22 December 2018 has generated a huge gap in the readiness of the Indonesian early warning system to detect such an event. Consequently, the official was found it difficult to broadcast the right warning within a considerable time to the local residences to evacuate or take necessary actions, which resulted in the loss of life and properties. There were more than 430 people died, and countless properties were destroyed when the tsunami swept the coastlines of southern Sumatra and western Java. While, this event is among the perfect events to study about the subaerial slide since it was occurred on near-surface with moderate magnitude M5.9 and creates the subaerial slide during the process (flank collapsed), and the broadband seismic stations managed by the Agency for Meteorology, Climatology, and Geophysics (BMKG) are already established and record the signal. Usually, the seismic source from the eruption was not complicated, and the seismic signal that recorded by the BMKG broadband seismic stations should correspond to the subaerial slide processes. Since Indonesia is an archipelago nation, the seismic station managed by the BMKG is distributed on the island with a distance ranging from a couple of kilometers to a tenth of kilometers away between stations. For this reason, this study tries to highlight several important suggestions in order to improve the detection using the signal recorded by the BMKG broadband seismic stations relate to such an event.
\end{abstract}

\section{Introduction}

The Krakatau volcanic eruption followed by the tsunami around Sunda strait (Indonesia) that occurred on 22 December 2018 was not the first-ever recorded event; unfortunately, it has repeatedly to occur. In recent history, it occurred in 1883, 1928, 1930, and 1981 [1]. Unfortunately, there were no acquisition devices available in that time and at the region to record the seismic wave energy for the events that were occurred in the $18-19$ centuries; thus, the mechanism of how the Krakatau volcanic eruption could generate a tsunami is still unclear [2-4]. At the end of 19 century and early 20 centuries, the Agency for Meteorology, Climatology, and Geophysics (BMKG) of Indonesia was established and operated the permanent seismic network distributed in the Indonesia region. With the increasing number of broadband digital seismic stations, it is possible nowadays to study this type of event.

The Anak Krakatau volcanic eruption followed by the tsunami on 22 December 2018 has generated a huge gap in the readiness of the Indonesian early warning system to detect such an event. Consequently, the official was found it difficult to broadcast the right warning within a considerable time to the local residences to evacuate or take necessary actions, which resulted in the loss of life and properties. There were more than 430 people died, and countless properties were destroyed when the tsunami swept the coastlines of southern Sumatra and western Java $[5,6]$. While this event is among the perfect events to study about the subaerial slide, i.e., it was occurred on a near-surface with low seismic magnitude M5.9 and created the subaerial slide during the process (flank collapsed). At the same time, the broadband seismic stations managed by the Agency for Meteorology, Climatology, and Geophysics (BMKG) are already established and record the signal. Usually, the seismic source from the volcanic eruption was not complicated, and the seismic signal that recorded by the BMKG broadband seismic stations should correspond to the subaerial slide processes. Since Indonesia is an archipelago nation, the seismic station managed by the BMKG is distributed on the island with a distance ranging from a couple of kilometers to a tenth of kilometers away between stations. For this reason, this study tries to highlight several important suggestions in order to improve the detection using the

*Corresponding author: haekal.azief.haridhi@unsyiah.ac.id 
signal recorded by the BMKG broadband seismic stations.

This study aims to evaluate the Indonesia early warning system from the existing BMKG broadband seismic stations on the event of the Anak Krakatau volcanic eruption event on 22 December 2018.

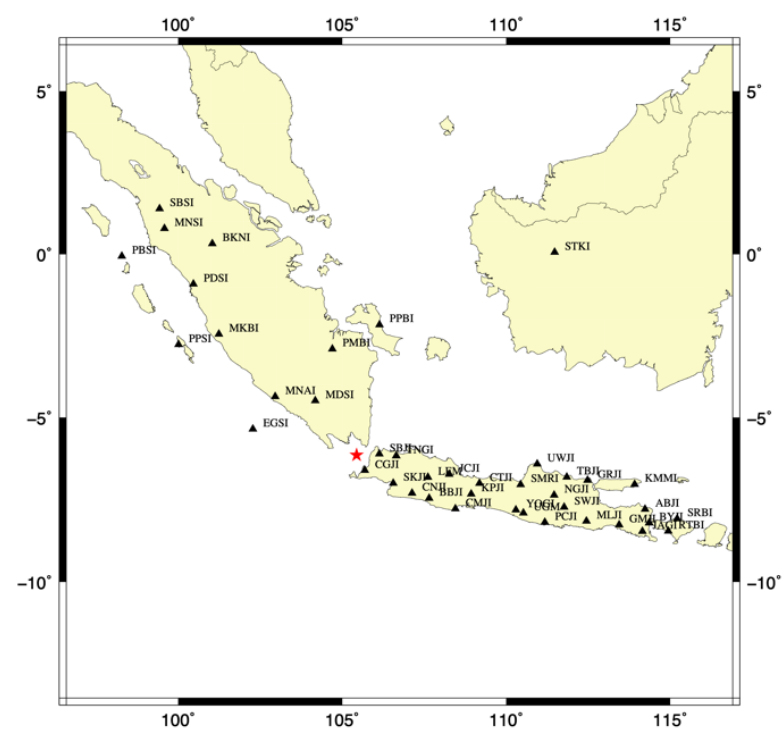

Fig. 1. The spatial distribution of the BMKG broadband seismic stations that recorded the 22 December 2018 Anak Krakatau volcanic eruption. The stations are indicated in the black triangle with text shown the key station name, and the red star indicates the Anak Krakatau event location.

\section{Methods}

The broadband signals of the Anak Krakatau eruption on 22 December 2018 were obtained upon request to the BMKG. As the data is received, all seismic records were deconvolved with their respective instrument responses to velocity by using the transfer function in SAC $[7,8]$. With all available stations, as shown in Fig.1, the signal is clearly observed and well recorded, as shown in Fig. 2. Then the manual picking of the event duration on the vertical, radial, and transversal components was done throughout all signals. It is commonly known that the low-frequencies surface waves of a large landslide could be recorded at the stations at long distances, while the high-frequency waves could be recorded with a distance up to a few hundred kilometers [9]. The landslide signals were obviously distinguishable from an earthquake signal; thus, the landslide signal usually observed has a short duration of less than $\sim 100$ seconds, has an impulse onset, unclear S-wave onsets. Therefore it is distinguishable between landslide and earthquake events $[9,10]$.

The low-frequencies surface wave recorded at the available stations reflects the series of unloading and reloading of the slide material to the sliding surface from the start of sliding-loading until the sliding process stopped. The high-frequency signal may indicate the scattering effect of the sliding material, such as debris clasts, therefore to estimate the landslide volumes, the low-frequency surface waves are used.
Then, the energy of the signals was calculated following the procedure described in [9], which uses the sum of the squared band-passed velocity signals as an energy parameter, as is seen in equation 1 .

$$
E=\Sigma_{t=t_{0}}^{t=t_{1}} v(t)^{2} d t
$$

Where $\mathrm{v}(\mathrm{t})$ is the $0.05 \mathrm{~Hz}$ low-pass filtered velocity record $(\mathrm{cm} / \mathrm{s})$ at time $t, t_{0}$ is the first arrival, while $t_{1}$ is the end of events durations, through the duration of the events indicated as T1 and T2 in Fig. 2 b.

Using the detailed studies of landslide and seismic energy done by $[9,10]$, we empirically derive an attenuation relation. A linear function with a constant slope is obtained through the resulted calculated energy from the observation in the function of distance [11]. The regress linear function follow the regress proposed by [9];

$$
\log _{10} E=\alpha \log _{10} R+\beta
$$

Where $\mathrm{R}$ is the source-station distance $(\mathrm{km}), \alpha$ is a constant slope, and $\beta$ is the intercept. Thus, the energy of the seismic wave at 0 distance or at the source could be predicted using equation 2 .

Due to the subaerial nature of landslides, the slide material volume is difficult to estimate. Therefore, we use the detailed study by [9] where, in their study, they compiled five landslide events and measured its associate slide material through airborne LiDAR topographic surveys. They proposed a linear relation that fit between the seismic wave energy and slide volume;

$$
\left.E\right|_{R=1 \mathrm{~km}}=8.5 \times 10^{-20} \mathrm{~V}^{2.06}
$$

Where $\mathrm{V}$ is the volume of the landslides.

Thus, we could predict how large the energy was at 0 distance or at the source. The predicted energy at 0 distance is then compared to the study done by [9] to empirically obtain the subaerial slide volume using equation 3 .

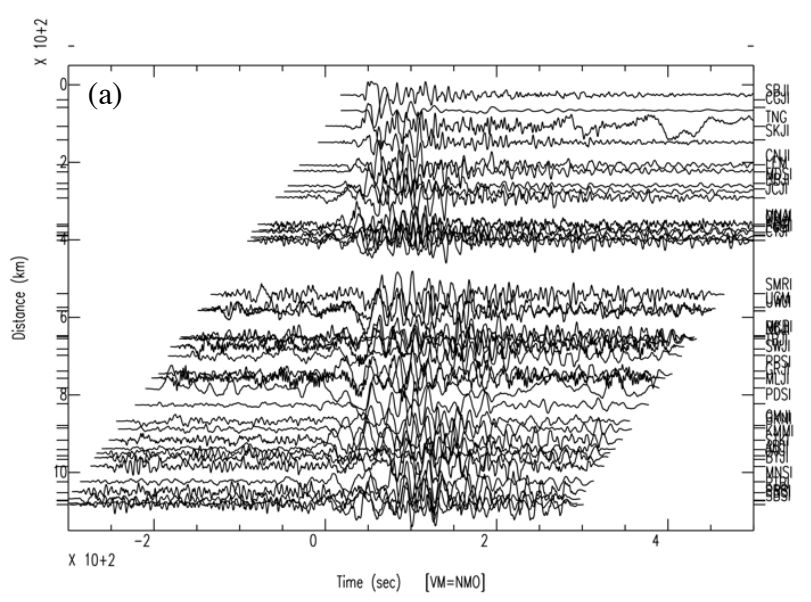




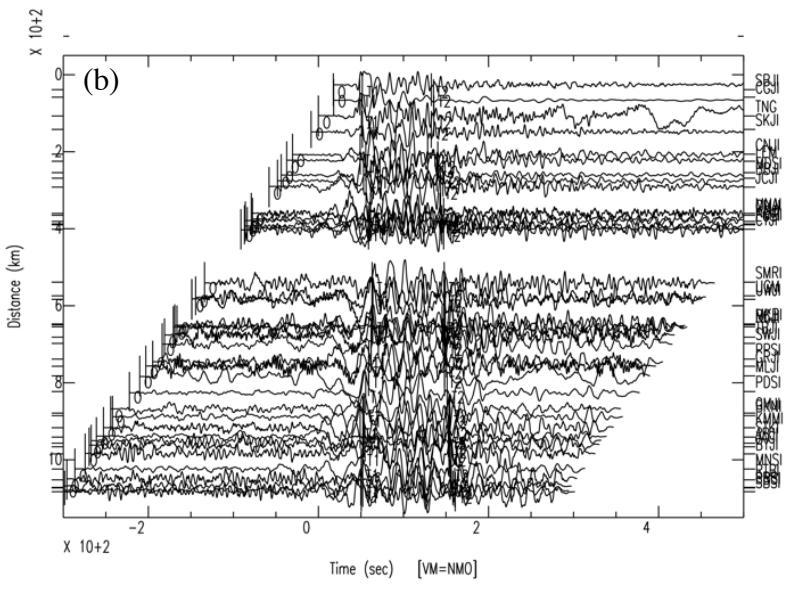

Fig. 2. The normal moveout (NMO) Signal Stacking Subprocess (SSS) with an apparent velocity of $3.2 \mathrm{~km} / \mathrm{s}$ of the available seismogram. The signals are low-pass filtered to 0.05 $\mathrm{Hz}$, with the $\mathrm{x}$-axis indicate the time in second, the left and right $y$-axis indicate the station distance and names, respectively. (a) The signal without picking the event duration, (b) with origin time, and picks of T1 and T2 indicate the start and end of the event durations.

\section{Results and discussion}

The studies of how large the volumes of the Anak Krakatau flank collapse or subaerial slide on the event of 22 December 2018 has been done using numerous approaches, i.e., Synthetic Aperture Radar (SAR) images analysis [12], inversion of tsunami wave model $[13,14]$, the Anak Krakatau eruption source and derived its slide volume with varying its single-force dip and basal friction [5], and the tsunami run-up studies [6].

However, it is essential to highlight the current state of the seismic broadband network to confirm the subaerial slide volumes resulting from the energy parameter through the information retrieved from the earlier studies. Even studies mentioned earlier have not come to a common term about how large the slide volume was; however, $\sim 0.004 \mathrm{~km}^{3}-\sim 0.2 \mathrm{~km}^{3}$ are in good agreement $[5,12]$.

Fig. 3 showed the resulted subaerial landslide is between $\sim 0.0001-\sim 0.0006 \mathrm{~km}^{3}$ obtained in this study. This result indicates that the volumes derived from the energy parameter through the distance of the available stations are ten times lower than the other studies mentioned earlier. Therefore, several factors need to be accounted, i.e., there is no observation within a considerable distance (probably several kilometers) from the source, which is the closest station that recorded this event is located at a distance of $50.2 \mathrm{~km}$ away; consequently, some energy already attenuates; the referenced studies for the empirical approach was not reliable to predict subaerial slide volumes; and the coverage azimuth of stations surrounding this event mostly on two angles $\sim 120^{\circ}$ and $\sim 280^{\circ}$, therefore, respective to the maximum slide volume trajectory the recorded signal was not sufficient. It is worth noted that since 2019 , BMKG is increasing the number of seismic stations in the Indonesia region.
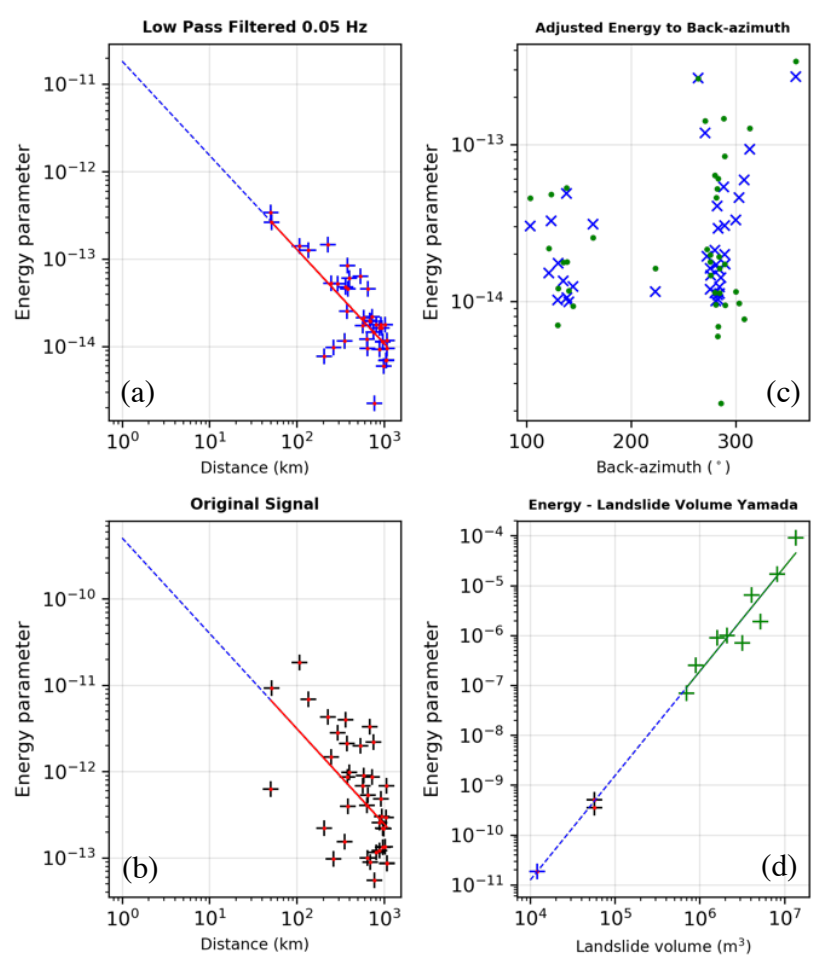

Fig. 3. (a) and (b) are shown the energy parameter against the distance, where the $y$-axis indicates the energy parameter and the $\mathrm{x}$-axis indicate the distance of the low-pass filtered and original signals, respectively. The plus symbol with the dot is obtained from the observation, and it empirically derives an attenuation relation linear regression is shown in the solid red line, with the dashed blue line as the prediction to the 0 distance. (c) Energy parameter against back-azimuth where the $y$-axis indicates the energy parameter and $x$-axis indicate the degree. The green dots symbol indicates the observed energy, while the blue $\mathrm{x}$ symbol indicates the normalized energy. (d) The energy parameter against landslide volumes, with the plus green symbol, are the detailed studies of the landslide at Japan done by [9] and predicted linear regression resulted from the observation in this studies is shown in the dashed blue line, and the observations for the low-pass filtered and original signal are shown as a plus symbol with blue and red colors, respectively.

Although the results indicate that the seismogram records as a promising approach to estimate the landslide or subaerial landslide volumes, however, to make this system available as part of the Early Warning System for landslide as well as the landslide-induced tsunami in Indonesia is still far from reliable. As the matter of fact, the closest to the Early Warning System for such feature is exhibited by Taiwan. Taiwan has developed a near real-time landquake monitoring system (NRLMS) [15], which successful to locate the landslide location, directions, and volume sizes via waveform inversion, with the entire process of location and volume determination taking a few seconds [16], thus allows the stakeholders to have the critical time to announce warnings and or take necessary actions. Further development of the Indonesia Early Warning System should consider the NRLMS. It offers the use of seismogram signal from the available seismic station managed by the BMKG with ease to implement, as well as it is cost-effective and efficient. Indonesia's Early 
Warning System should be adopted or it is suggested to developed such system as the NRLMS in Taiwan.

\section{Conclusion}

From this study, we have shown that the current seismic network has the potential to predict the subaerial landslide volumes, although, in this study, the result indicates it may be ten times larger than the landslide volume predicted in this study $\left(\sim 0.0001-\sim 0.0006 \mathrm{~km}^{3}\right)$. It is considered that the increasing amount of stations will make a reliable slide volume estimation from the seismic wave energy and could be made a possible threshold of a similar event and their slide volume that may generate a tsunami wave.

These important issues need to be addressed for the similar geological features and other tectonic features as well, i.e., faults extension from on land to offshore, such as Sumatra Fault Zone (SFZ), Palu-Koro fault, and others.

However, some additional task needs to be considered: (1) Increase the number of seismic stations at the concerned region with broadband and strong motion instrument available (co-site), (2) Data management and backup system (to reduce missing data from the offline stations), (3) Develop a near real-time monitoring trough seismic waveform inversion, and (4). Enhanced communication infrastructure to quickly broadcast the early warning messages to the concerned society.

Although, at the moment the early warning system in Indonesia to detect a landslide event is unreliable, however, further development should consider the use of the seismogram records and inversion to quickly locate, and determine the landslide volumes.

Not only that, but it is also extremely important to enhance the community resilience through tsunami drills and or disaster preparedness at the concerned region so that the society at those concerned locations has the ability to manage when this event and or any other disaster events occur.

Acknowledgment. We would like to thank the BMKG for the continuous collaboration and made the seismograms available for this study. Sincere thanks are due to the TDMRC for their effort in organizing the 13th Aceh International Workshop and Expo on Sustainable Tsunami Disaster Recovery (AIWESTDR). This research is funded by the Ministry of Education, Culture, Research, and Technology through Universitas Syiah Kuala, under the Research Institutions and Community Service with contract number: 169/UN11/SPK/PNBP/2021. The writing of this manuscript is supported by the Matching Fund - Kedaireka funded by the Ministry of Education, Culture, Research, and Technology Indonesia awarded to the Research Center for Marine Sciences and Fisheries, Universitas Syiah Kuala. The Generic Mapping Tools is being used to draw the map figure [17].

\section{References}

1. NGDC, 2019 (2019)

2. P. W. Francis, J. Volcanol. Geotherm. Res. 25, 349 (1985)

3. N. Nomanbhoy and K. Satake, Geophys. Res.
Lett. 22, 509 (1995)

4. I. Yokoyama, J. Volcanol. Geotherm. Res. 9, 359 (1981)

5. L. Ye, H. Kanamori, L. Rivera, T. Lay, Y. Zhou, D. Sianipar, and K. Satake, Sci. Adv. 6, 1 (2020)

6. Syamsidik, Benazir, M. Luthfi, A. Suppasri, and L. K. Comfort, Nat. Hazards Earth Syst. Sci. 20, 549 (2020)

7. P. Goldstein, D. Dodge, M. Firpo, and L. Minner, Int. Geophys. 81, 1613 (2003)

8. P. Goldstein and A. Snoke, Inc. Institutions Seismol. Data Manag. Cent. Electron. Newsl. (2005)

9. M. Yamada, Y. Matsushi, M. Chigira, and J. Mori, Geophys. Res. Lett. 39, 1 (2012)

10. M. Yamada, H. Kumagai, Y. Matsushi, and T. Matsuzawa, Geophys. Res. Lett. 40, 2998 (2013)

11. H. Kanamori, J. I. M. Mori, E. Hauksson, T. H. Heaton, K. Hutton, and L. M. Jones, Bull. Seismol. Soc. Am. 83, 330 (1993)

12. R. Williams, P. Rowley, and M. C. Garthwaite, Geology 47, 973 (2019)

13. M. Heidarzadeh, T. Ishibe, O. Sandanbata, A. Muhari, and A. B. Wijanarto, Ocean Eng. 195, 106733 (2020)

14. A. Muhari, M. Heidarzadeh, H. Susmoro, H. D. Nugroho, E. Kriswati, Supartoyo, A. B. Wijanarto, F. Imamura, and T. Arikawa, Pure Appl. Geophys. 176, 5219 (2019)

15. W. A. Chao, Y. M. Wu, L. Zhao, H. Chen, Y. G. Chen, J. M. Chang, and C. M. Lin, Sci. Rep. 7, 1 (2017)

16. W. A. Chao, T. R. Wu, K. F. Ma, Y. T. Kuo, Y. M. Wu, L. Zhao, M. J. Chung, H. Wu, and Y. L. Tsai, Seismol. Res. Lett. 89, 1335 (2018)

17. P. Wessel and W. H. F. Smith, Eos, Trans. Am. Geophys. Union 79, 579 (1998) 